\title{
ESTRATÉGIA DE COMERCIALIZAÇÃO EM MERCADOS DERIVATIVOS - DESCOBRIMENTO DE BASE E RISCO DE BASE DA CAFEICULTURA EM DIVERSAS LOCALIDADES DE MINAS GERAIS E SÃO PAULO
}

\author{
Marketing strategy in derivative markets discovery of the basis and the risk of basis \\ of coffee in several places in Minas Gerais and São Paulo states
}

\author{
Renato Elias Fontes ${ }^{1}$, Luiz Gonzaga de Castro Junior ${ }^{2}$, Adriano Freitas Azevedo ${ }^{3}$
}

\begin{abstract}
RESUMO
Com o presente trabalho tem-se por objetivo geral mensurar os valores da base e do risco de base da atividade cafeeira de importantes cidades produtoras de café localizadas no Estados de Minas Gerais e São Paulo, pois a estratégia de se utilizar os mercados derivativos vem ganhando cada vez mais importância, devido às suas características, que propiciam o feitio de 'hedge'" de preços. Os municípios estudados foram Boa Esperança, Caratinga, Lavras, Machado, Patrocínio, Três Pontas, Varginha e Garça (SP). Os dados primários utilizados sobre o preço da saca de café comercializada no mercado local foram coletados diretamente nas instituições participantes, e o preço do café no mercado futuro foi levantando junto à BM\&F. A diversidade dos valores da base e do risco de base encontrada demonstra que cada localidade apresenta características próprias de comercialização, e todas as localidades apresentam valores negativos. A época de comercialização é um importante fator a ser levado em consideração, pois na safra há um fortalecimento da base e o risco de base é menor do que na entressafra, que apresenta um enfraquecimento da base.
\end{abstract}

TERMOS PARA INDEXAÇÃO: Café, Base, Risco de Base.

\begin{abstract}
The general objective of this assignment is to measure the value of the basis and of the risk of basis of the cultivation of coffee in important coffee producer cities from the states of Minas Gerais and São Paulo, for the strategy of using the derivative markets has been obtaining more importance due to its characteristics that provide the hedge of the prices. The cities studied were Boa Esperança, Caratinga, Lavras, Machado, Patrocínio, Três Pontas, Varginha and Garça (SP). The primary data used was, the local price of the coffee bag. The data was collected directly from the participant institutions and the future price of the coffe was raised with the BM\&F. The variety of the values of the basis and of the risk of basis found shows that each locality presents its own commerce characteristics and all of them present negative values. The period of commercialization is an important issue and so should be considered, because during the crop havest there is a strengthening of the basis, altrough and the risk of basis is lower than it is between the crop havests, when there is a weakening of the basis.
\end{abstract}

INDEX TERMS: Coffee, Basis, Risk of Basis.

(Recebido para publicação em 26 de maio de 2003 e aprovado em 10 de maio de 2004)

\section{INTRODUÇÃO}

A agricultura, de maneira geral, apresenta fatores variáveis característicos, o que a classifica como sendo um mercado em que se aproxima da concorrência perfeita. Um dos principais problemas que essas características acarreta é em relação à precificação, uma vez que o produtor rural apresenta-se como tomador de preço. Inserida nesse mercado, a cafeicultura reflete o grave problema da instabilidade de preços, pois, com isso, os cafeicultores ficam a mercê das variações de preço do seu produto na hora da venda, tornando o gerenciamento de sua atividade cada vez mais complexo e arriscado.
Para Fontes (2001), é necessário que o cafeicultor adote uma postura mais empresarial, agindo com racionalidade administrativa e utilizando os diversos instrumentos produtivos, financeiros e comerciais disponíveis, que vão lhe propiciar essa racionalidade. Com o desenvolvimento do setor terciário, houve a criação de firmas que prestam diversos serviços aos empresários cafeicultores, realizando o processo denominado de terceirização da atividade; com isso, cria-se condição facilitadora para se efetuar desde uma simples operação de manejo da lavoura, até operações mais complexas, como a comercialização da commodity café.

1. Doutorando em Administração/DAE - Universidade Federal de Lavras - Caixa Postal 3037 - 37.200-000 - Lavras, MG - refontes@ufla.br

2. Professor Dr. Departamento de Administração e Economia/UFLA.

3. Mestrando em Administração - DAE/UFLA. 
Estratégia, segundo Oliveira (1991), está relacionada à ligação da empresa ao seu ambiente, em que essa busca definir e operacionalizar estratégias que maximizem os resultados da interação estabelecida. A finalidade das estratégias empresariais é estabelecer quais serão os caminhos, os cursos, os programas de ação que devem ser seguidos para alcançar os objetivos estabelecidos pela empresa. Certo \& Peter (1993) definem estratégia sob um enfoque administrativo, em que essa é um processo contínuo interativo que visa a manter uma organização como um conjunto apropriadamente integrado a seu ambiente, agindo segundo etapas definidas e de forma contínua.

Diversas estratégias, isoladas ou conjuntas, podem ser utilizadas pelos empresários cafeicultores para comercializar o café, mas o processo de comercialização do café é feito basicamente com o produto físico, em que os cafeicultores vendem diretamente para os compradores ou utilizam a intermediação da cooperativa para a venda. A comercialização do café em mercados derivativos, seja por bolsa de mercadorias e/ou por Cédula do Produto Rural (CPR), ainda é pouco usada, mas vem ganhando importância, pois, com a tendência da profissionalização da cafeicultura, a utilização de mecanismos que garantam preços para os cafeicultores, será cada vez mais ampliada. Conforme Teixeira (1992), os mercados futuros constituem-se no instrumento de mercado mais eficaz para eliminar o risco da variação de preços dos bens econômicos.

Segundo Fileni (1999), a falta de conhecimento operacional e as incertezas em relação ao comportamento relativo dos preços futuros e à vista contribuem para a pequena participação do mercado futuro durante a comercialização agrícola.

De acordo com Arbex \& Carvalho (1999), o mercado futuro de café brasileiro é o mais desenvolvido entre os produtos agrícolas nacionais, com o maior volume de negociação entre os contratos agropecuários na Bolsa de Mercadorias \& Futuros (BM\&F). A comercialização em mercados derivativos pode ser classificada em contratos a termo, a futuro e de opção. Conforme Castro Júnior et al. (1997), nos contratos a termo, o comprador e o vendedor definem um preço e efetuam a operação de compra ou venda antes mesmo da disponibilidade do produto. Nesse tipo de contrato, pode ou não haver adiantamento de recursos, e os contratos são sempre liquidados por entrega da mercadoria ao preço combinado. A Cédula do Produto Rural (CPR) é um exemplo, sendo garantida por diversas instituições, permitindo que o cafeicultor venda sua safra antecipadamente, adquirindo recursos financeiros para o processo produtivo e para armazenamento do produto. Segundo Nuevo (1996), o principal motivo da instituição da CPR pelo governo foi de poder oferecer ao mercado de crédito agrícola mais um instrumento de financiamento da produção; porém, um instrumento que fosse simples, eficaz, com baixo custo operacional e com sólidas garantias para as partes envolvidas.

O contrato futuro é uma outra forma de comercialização que se diferencia do contrato a termo. A diferença entre eles é que no contrato a termo o comprador e o vendedor ficam obrigados até o vencimento e liquidam o contrato mediante a entrega física do produto. No mercado futuro, tanto o comprador quanto o vendedor são livres para saírem do contrato, invertendo suas posições, quando assim desejarem. O contrato futuro tem por objetivo estabelecer todas as condições de transação, menos a cotação do produto e menos de $2 \%$ das liquidações do contratos é feita por entrega física do produto.

Existem dois tipos de contrato de opções, venda e compra, as quais conferem respectivamente aos portadores desses contratos o direito de exercer ou não o direito de venda ou compra do objeto de negociação em determinada data e por um certo preço. A vantagem desse contrato sobre o contrato futuro está relacionada ao estabelecimento de preço mínimo de venda ou compra; as possibilidades de ganhos extras são ilimitados, não há chamada de margem de garantia, pagamentos de ajustes diários e existem vários níveis de seguro de preço a serem escolhidos. Maiores detalhes sobre o contrato futuro e de opções de café arábica da Bolsa de Mercadorias \& Futuros (BM\&F), consultar Schouchana (2000).

Os mercados futuros possibilitam alternativas variadas de instrumentos de comercialização de produtos agropecuários. Dependendo do tipo de contrato comercializado, eles atendem a pelo menos uma das seguintes funções: proteção contra variação adversa de preço; e garantia de mercado. Esses instrumentos têm alguns custos que devem ser levados em conta na tomada de decisão de comercialização. As diferentes formas de contratos futuros devem ser encaradas como instrumentos adicionais que podem e devem ser levadas em consideração no gerenciamento da atividade de comercialização agrícola. São instrumentos úteis para fins específicos (AGUIAR, 1999).

A principal finalidade do mercado derivativo é a fixação de preço da commodity, eliminando o risco da variação de preço, pois há uma inter-relação de interferência entre os preços futuros e os preços à vista do mercado físico. Quando o cafeicultor busca a comercia- 
lização no mercado derivativo, ele procura realizar o hedge, que consiste no ato de defesa contra variações futuras adversas no preço. Os hedgers são agentes de mercado que têm interesse na commodity negociada. Podem ser cafeicultores, beneficiadoras, torrefadoras, exportadores, etc. Para a realização do hedge, é necessário que existam agentes dispostos a correr o risco da variação de preço, pois o que ocorre com o hedge é a transferência do risco de variação do preço da commodity para outros hedgers ou outros agentes dispostos a assumir tal risco, os especuladores. Apesar da imagem negativa que se tem deles, esses são de suma importância para a operacionalização do mercado derivativo, uma vez que são os responsáveis pela liquidez no mercado.

Quando o cafeicultor realiza o hedge, ele elimina totalmente o risco de variação do preço, mas passa a sofrer o risco da variação da base. Conforme Hull (1996) e Leuthold et al. (1989), a base é considerada como sendo a diferença do preço da commodity no mercado físico à vista, na praça local de comercialização, e o preço futuro para determinado mês de vencimento do contrato. Para que haja um hedge perfeito, é necessário que o valor da base observada seja mantida inalterada no decorrer do tempo até a expiração do contrato, pois, assim sendo, o preço da commodity no mercado futuro será igual ao preço da commodity no mercado físico local; porém, isso dificilmente ocorre na prática, pois as variáveis: prêmio pelo risco, taxa de juros, custo de carregamento, transporte e armazenamento, localização da praça, qualidade do produto e características intrínsecas da comercialização vão interferir na sua formação. O risco de base é dado pela variância da base no momento em que o hedge é encerrado, de acordo com a percepção do risco no momento em que ele é iniciado.

$\mathrm{O}$ valor da base pode ser positivo, quando o preço à vista da localidade for maior que a cotação do preço no mercado futuro, e pode ser negativo, quando o preço à vista da localidade for menor que a cotação do preço no mercado futuro. Quando a variação do preço à vista cresce mais do que a variação do preço futuro, diz-se que houve um fortalecimento de base, e o inverso, diz-se que houve um enfraquecimento de base. Portanto, quanto menor for o risco de base, maior será a utilidade dos contratos futuros como mecanismo de transferência de risco e maior garantia de preço para os hedgers, propiciando uma maior utilidade do mercado derivativo como instrumento de gerenciamento da comercialização.

Sendo assim, com este trabalho tem-se por objetivo identificar a base e o risco de base em diversas localidades produtoras de café, para que se possa subsidiar de informações específicas os cafeicultores locais e as corretoras que trabalham nessas localidades.

\section{MATERIAL E MÉTODOS}

\section{Considerações do Estudo}

A área de estudo compreende os municípios mineiros de Boa Esperança, Caratinga, Lavras, Machado, Patrocínio Três Pontas e Varginha e o município paulista de Garça. Essas cidades foram escolhidas por terem representatividade em termos de produção e comercialização de café, além de serem centros geradores de informações do mercado cafeeiro.

O levantamento dos dados primários, ou seja, os preços de café físico negociados na praça foram realizados por meio de coletas direta nas instituições participantes e, para o levantamento dos dados secundários, no caso do preço futuro, foi cotado o preço de ajuste diário do contrato de café arábica, que foi obtido no site da BM\&F (www.bmf.com.br).

A série de dados de preços futuros utilizados compreende o período de setembro de 1994 a julho de 2001. No caso dos preços no mercado físico, cada praça apresentou uma série própria de dados, com característica bastante heterogênea, pois houve dia de negociação no futuro em que não houve negociação no mercado físico local e também, por falta de dados arquivados, não foi possível a mensuração homogênea para todas as localidades. Quando no mesmo dia apresentava mais de um preço de negociação, utilizava-se o de maior valor ou aquele preço de café que se encaixava nas características de qualidade semelhante ao determinado pelo contrato de café BM\&F. Os valores utilizados foram o valor do preço físico bruto faturado, sem os descontos posteriores.

Os preços futuro em dólares foram transformados para valores em reais; a cotação utilizada foi a do dólar comercial do dia, igualando assim ao mesmo padrão monetário dos preços cotados no mercado físico.

$\mathrm{O}$ valor da base foi obtido pela diferença entre o preço à vista e o preço futuro, segundo a expressão:

$$
\mathrm{Bt}, \mathrm{T}=\mathrm{St}-\mathrm{Ft}, \mathrm{T}
$$

Em que: Bt, $\mathrm{T}$ = é o valor da base no período $\mathrm{t}$, para o mês de vencimento $\mathrm{T}$; $\mathrm{St}=\mathrm{o}$ preço no mercado físico (Spot) no período t, e Ft, T = é o preço futuro em $\mathrm{t}$, para o mês de vencimento $\mathrm{T}$.

Após encontrar o valor de cada base, essas foram agrupadas no mesmo período de vencimento de contrato e feita a média aritmética do vencimento segundo a expressão: 


$$
\text { BMeT }=\frac{1}{\mathrm{n}} \sum_{\mathrm{n}}^{1} \mathrm{Bt}, \mathrm{T}
$$

Em que: BMeT = é o valor da base média, para o mês de vencimento $\mathrm{T} ; \mathrm{Bt}, \mathrm{T}=$ é o valor da base no período $\mathrm{t}$, para o mês de vencimento $\mathrm{T}$, e $\mathrm{n}$ = é o número de bases encontradas no mês de vencimento $\mathrm{T}$.

O risco de base foi quantificado pelo valor do desvio-padrão das bases encontradas, representado pela seguinte expressão:

$$
\mathrm{RB}=\sqrt{\frac{1}{\mathrm{n}-1}\left(\sum \mathrm{Bt}, \mathrm{T}-\mathrm{BMeG}\right)^{2}}
$$

Em que: $\mathrm{RB}=$ é o valor do risco de base; $\mathrm{BMeG}$ = é o valor da base média geral; $\mathrm{Bt}, \mathrm{T}=$ é o valor da base no período t, para o mês de vencimento $\mathrm{T}$, e $\mathrm{n}=$ é o número de bases encontradas da amostra;

Para a avaliação dos valores das bases, foram utilizados no mês de vencimento de cada contrato futuro os últimos 6 (seis) valores diários negociados por contrato, pois o preço do mercado físico e do mercado futuro tendem a se aproximar e a diferença entre eles é somente o valor da base, excluindo a variável tempo na formação da base. A partir dessas bases, foram encontrados a base média por período e o risco de base para cada localidade. Utilizou-se também a divisão da série em safra e entressafra, em que foi possível determinar o valor da base média e o risco de base da safra e entressafra, como também os valores da base dos meses que compõem o período.

\section{RESULTADOS E DISCUSSÃO}

Na Tabela 1 apresentam-se os valores médios das bases para diversos vencimentos, a base média geral e o risco de base. De uma maneira geral, todas as localidades pesquisadas apresentaram uma grande variação nos valores da base, representado pela especificidade da estrutura das organizações na sua conduta de comercialização do café, distância da localidade até São Paulo/SP e pela qualidade do produto. Em todos os vencimentos e localidades analisadas, a base foi negativa, demonstrando que o preço cotado na BM\&F é um balizador para a formação do preço no mercado local, pois, a partir do preço cotado na $B M \& F$ é que se faz a subtração das despesas incorridas, principalmente na armazenagem, transporte, serviços de corretagem e impostos oriundos da comercialização do café, além da característica qualitativa do café. Somente nos períodos de contrato referente ao vencimento de maio de 2001 na localidade de Varginha/MG, e março de 1996 em Patrocínio/MG, apresentou base positiva em Varginha/MG no valor de R\$ 5,79, ou seja, o valor da saca de café negociado na localidade foi $\mathrm{R} \$$ 5,79 mais alto que a saca de café cotada na BM\&F, e em Patrocínio R\$ 0,71. Pode-se explicar esse fato por uma excepcionalidade na hora de comercialização, em que o mercado se encontrava em uma situação invertida, provavelmente ocasionada pela falta de oferta momentânea do produto no mercado local; com isso, o comercializador conseguiu um preço superior.

Em relação aos meses de vencimento, o contrato referente ao mês de dezembro do ano de 1999 foi o que apresentou as maiores bases negativas nas localidades, exceto Boa Esperança, que teve no período do contrato de março/97 a sua maior base negativa, e Lavras, em dezembro de 1997. Varginha apresentou o maior valor da base negativa; com isso, nesse período, o valor da saca de café negociado na localidade ficou R\$ -80,93 abaixo do valor cotado da saca de café na $\mathrm{BM} \& \mathrm{~F}$.

Para todas as localidades, os valores da base para os períodos de vencimento apresentaram características heterogêneas, o que demonstra um processo de fortalecimento e enfraquecimento de base de forma aleatória, em que esse não segue um caminho pré-definido de resposta entre a relação do preço físico e o preço no mercado futuro.

A localidade que apresentou a base média menor foi Machado/MG, R\$ -28,69 - o fato que pode explicar esse valor é que os dados coletados para as análises foram fornecidos por uma empresa particular de comercialização de café; com isso, para bancar todas as despesas inerentes ao processo de comercialização e ainda auferir lucro, é necessário cotar o café no mercado local a um preço menor. Em Patrocínio/MG, foi encontrado o menor valor da base média, $\mathrm{R} \$$-15,83; isso pode estar associado à sua localização, Triangulo Mineiro, região onde o agronegócio café é muito bem organizado, já que se investe no marketing da qualidade do produto e, conseqüentemente, se conseguem preços melhores para os produtos locais.

Três Pontas/MG foi a localidade que apresentou o menor valor do risco de base; com isso, os valores da base encontrados nessa localidade variam para mais ou para menos em R\$ 9,50. Sendo Três Pontas/MG. Uma das principais localidades produtoras de café do mundo, o risco de base demonstram que a utilização do mercado futuro para os produtores locais pode ser de grande utilidade. Caratinga/MG foi a localidade que apresentou o maior risco de base, $\mathrm{R} \$ 17,65$, não diferindo muito de Boa Esperança/MG, com o risco de base de $\mathrm{R} \$ 17,00$. No geral, os resultados do risco de base demonstra que o mercado futuro pode ser usado com eficiência para as localidades estudadas. 
TABELA 1 - Base média por período, base média geral e risco de base em R\$/Saca de $60 \mathrm{Kg}$. por localidade e por vencimento de contrato.

\begin{tabular}{|c|c|c|c|c|c|c|c|c|}
\hline \multirow[b]{2}{*}{ Vencimento } & \multicolumn{8}{|c|}{ Localidades } \\
\hline & $\begin{array}{c}\text { Boa } \\
\text { Esperança }\end{array}$ & Caratinga & Lavras & Machado & Patrocínio & Três Pontas & Varginha & Garça \\
\hline Set/94 & --- & --- & --- & $-32,97$ & $-14,67$ & ---- & --- & $-40,51$ \\
\hline Dez/94 & ---- & ---- & ---- & $-10,25$ & $-09,15$ & ---- & ---- & $-21,48$ \\
\hline Mar/95 & ---- & ---- & $-31,51$ & $-10,89$ & $-21,54$ & ---- & $-29,86$ & $-14,07$ \\
\hline Mai/95 & ---- & $-12,21$ & ---- & ---- & $-06,04$ & ---- & $-15,21$ & $-11,42$ \\
\hline Jul/95 & ---- & $-04,63$ & $-03,83$ & $-01,20$ & $-02,22$ & --- & $-09,25$ & $-06,92$ \\
\hline Set/95 & ---- & $-15,20$ & $-11,90$ & $-14,39$ & $-14,16$ & --- & $-08,35$ & $-13,54$ \\
\hline Dez/95 & ---- & $-09,02$ & $-03,73$ & ---- & $-05,41$ & ---- & $-03,90$ & $-07,44$ \\
\hline Mar/96 & ---- & $-04,74$ & $-03,25$ & $-02,23$ & 00,71 & ---- & $-01,73$ & $-02,95$ \\
\hline Mai/96 & ---- & $-21,00$ & $-08,19$ & $-09,07$ & $-13,41$ & ---- & $-07,75$ & $-10,24$ \\
\hline Jul/96 & ---- & $-16,70$ & $-07,60$ & $-13,30$ & $-11,51$ & ---- & $-23,31$ & $-03,51$ \\
\hline Set/96 & --- & $-17,05$ & $-08,91$ & $-08,48$ & $-08,63$ & ---- & $-09,14$ & $-11,13$ \\
\hline Dez/96 & $-18,95$ & $-28,95$ & $-22,80$ & $-19,67$ & $-18,00$ & $-21,17$ & $-25,74$ & $-19,83$ \\
\hline Mar/97 & $-67,00$ & $-40,63$ & ---- & $-42,30$ & $-24,48$ & $-34,00$ & $-30,48$ & $-30,48$ \\
\hline Mai/97 & $-22,42$ & $-35,36$ & ---- & $-32,76$ & $-10,46$ & $-27,81$ & $-31,78$ & $-17,96$ \\
\hline $\mathrm{Jul} / 97$ & $-48,98$ & $-39,08$ & ---- & ---- & $-22,89$ & $-27,75$ & $-23,09$ & $-38,55$ \\
\hline Set/97 & $-15,75$ & --- & ---- & $-22,96$ & $-16,44$ & $-27,77$ & $-14,67$ & $-26,11$ \\
\hline Dez/97 & $-26,00$ & $-42,84$ & $-49,46$ & $-46,12$ & $-22,03$ & $-25,50$ & $-23,93$ & $-22,53$ \\
\hline Mar/98 & $-28,93$ & $-20,19$ & $-49,19$ & $-29,53$ & $-13,64$ & $-28,48$ & $-15,44$ & $-18,64$ \\
\hline Mai/98 & $-29,92$ & $-48,85$ & $-22,97$ & $-36,22$ & $-24,92$ & $-30,09$ & $-41,96$ & $-28,59$ \\
\hline $\mathrm{Jul} / 98$ & $-14,12$ & $-17,39$ & ---- & $-20,00$ & $-12,45$ & $-17,27$ & $-09,96$ & $-16,78$ \\
\hline Set/98 & $-19,75$ & $-26,12$ & $-17,75$ & $-30,48$ & $-19,23$ & $-24,07$ & $-12,86$ & $-23,73$ \\
\hline Dez/98 & $-26,59$ & $-29,00$ & ---- & $-26,59$ & $-20,04$ & $-26,54$ & $-33,82$ & $-24,20$ \\
\hline Mar/99 & $-08,82$ & $-24,04$ & $-15,14$ & $-21,77$ & $-11,07$ & $-17,91$ & $-07,59$ & $-16,57$ \\
\hline Mai/99 & $-14,35$ & $-38,30$ & ---- & $-19,77$ & $-12,18$ & $-20,35$ & $-21,78$ & $-19,68$ \\
\hline $\mathrm{Jul} / 99$ & $-15,82$ & $-22,96$ & $-25,04$ & $-23,92$ & $-17,99$ & $-24,34$ & $-16,94$ & $-29,32$ \\
\hline Set/99 & $-15,14$ & $-30,09$ & $-15,14$ & ---- & $-13,91$ & $-21,72$ & $-06,19$ & $-24,08$ \\
\hline Dez/99 & $-46,22$ & $-53,90$ & $-46,32$ & $-59,59$ & $-37,50$ & $-54,69$ & $-80,93$ & $-61,50$ \\
\hline Mar/00 & $-23,00$ & $-31,37$ & $-25,98$ & $-33,15$ & $-23,92$ & $-35,09$ & $-18,09$ & $-33,59$ \\
\hline Mai/00 & $-15,82$ & $-19,86$ & $-18,01$ & $-26,05$ & $-14,38$ & $-37,91$ & $-20,80$ & $-20,21$ \\
\hline $\mathrm{Jul} / 00$ & $-24,92$ & $-37,20$ & $-06,76$ & $-35,04$ & $-30,03$ & $-28,98$ & $-37,52$ & $-41,37$ \\
\hline Set/00 & $-19,98$ & $-24,72$ & ---- & $-30,39$ & $-20,48$ & $-30,31$ & $-21,02$ & $-23,98$ \\
\hline Dez/00 & $-29,27$ & $-25,17$ & $-25,52$ & $-29,06$ & $-23,15$ & ---- & $-16,08$ & $-24,48$ \\
\hline Mar/01 & $-06,65$ & ---- & $-12,14$ & $-17,94$ & $-06,64$ & ---- & $-09,13$ & $-10,81$ \\
\hline Mai/01 & $-19,09$ & ---- & $-22,59$ & $-28,69$ & $-16,45$ & ---- & 05,79 & ---- \\
\hline $\mathrm{Jul} / 01$ & ---- & ---- & $-22,83$ & ---- & ---- & ---- & ---- & ---- \\
\hline $\begin{array}{l}\text { Base Média } \\
\text { Geral }\end{array}$ & $-24,24$ & $-26,30$ & $-20,06$ & $-28,69$ & $-15,83$ & $-27,86$ & $-19,45$ & $-21,70$ \\
\hline Risco de Base & 17,00 & 17,65 & 15,31 & 12,38 & 10,29 & 09,50 & 16,76 & 13,81 \\
\hline
\end{tabular}

FONTE: Dados da pesquisa.

Ciênc. agrotec., Lavras, v. 29, n. 2, p. 382-389, mar./abr., 2005 
Interessante ressaltar a diferença entre os valores da média geral da base e o risco de base da cidade de Três Pontas/MG e Varginha/MG, onde os valores têm acentuada diferença, que não se justifica pela distância, pois são localidades bem próximas, e nem pela qualidade do café, pois ambas apresentam bastante semelhança qualitativa. Pode-se justificar essa diferença pela capacidade intrínseca de cada organização na ação de comercializar o seu café, o que traz vantagens e desvantagens para ambas as localidades.

Na Tabela 2 são apresentados os valores das bases e o risco de base separados em anos. Analisando as bases anuais das localidades, essas novamente apresentam a característica heterogênea, em que os valores das bases apresentam-se de forma bastante diferente entre as localidades. De maneira geral, a base média apresenta uma variação de enfraquecimento de base em um ano para o fortalecimento de base no ano subseqüente. Pode-se explicar esse fato por causa da característica de bianualidade do cafeeiro, em que se segue um período de alta produção com período de queda na produção, o que vai interferir na oferta do produto no mercado e, conseqüentemente, no seu preço e na forma de comercialização.

Para as localidades de Boa Esperança/MG, Lavras/MG, Machado/MG e Varginha/MG, o ano de 1997 foi o que apresentou a base média maior, ou seja, foi o período de maior enfraquecimento da base. Lavras/MG obteve a maior base média $(\mathrm{R} \$-49,46)$ de todos os dados analisados. No ano de 2000, a base média das localidades apresentou valores que não diferem de forma expressiva, mantendo um certo padrão do valor, em que o menor valor encontrado foi o de Lavras/MG, R\$ -20,04, e o maior foi de Três Pontas/MG, R\$ -30,65.

Vale ressaltar que as localidades de Patrocínio/MG e Garça/SP, com exceção do ano de 1996, apresentam um processo de oscilação de fortalecimento e enfraquecimento da base de forma semelhante. Apesar de estarem em regiões diferentes, o café comercializado dessas regiões apresentam-se no mercado como cafés de qualidade superior e, também, os dados coletados para a amostra dessas localidades foram oriundos de uma mesma organização, o que garante uma certa padronização na forma de manuseio e comercialização do produto, o que propicia essa particular semelhança. Porém, os valores são diferentes em virtude da descentralização da ação de comercialização e por características próprias inerentes à capacidade e estrutura de negociação que os comercializadores possuem a sua disposição.

Patrocínio/MG foi a localidade que apresentou os valores do risco de base mais constantes durante a série de tempo analisada; esse fato possivelmente ocorre devido às características organizacionais da referida região e também à própria estrutura da organização responsável pela comercialização do café.

Na Tabela 3 Verificam-se os valores das bases separados em safra e entressafra e por mês de vencimento de contrato e o risco de base da safra e entre safra. Em todas as localidades ocorreu um fortalecimento da base na safra e um enfraquecimento da base na entressafra.

$\mathrm{O}$ risco de base, exceto para a localidade de Caratinga, seguiu a mesma tendência, sendo maior na entressafra do que na safra. Esse fato é esperado, pois nesse período há uma maior incerteza na formação do preço, ocasionado principalmente por informações especulativas, previsões de safras e pela probabilidade de ocorrer problemas climáticos e até mesmo catástrofes nos países produtores, o que vai prejudicar a produção e afetar a oferta do café no mercado.

A cidade de Três Pontas/MG foi a que apresentou o maior enfraquecimento de base na safra; com isso, o preço do café na localidade foi, em média, R\$25,95 menor do que o preço médio cotado na BM\&F na época da safra; porém, foi a localidade que apresentou o menor risco de base, ou seja, a base variou para mais ou para menos em até $\mathrm{R} \$ 8,04$, o que facilita a tomada de decisão para comercializar. Lavras/MG teve a menor base na safra, R\$14,70, e Caratinga/MG apresentou o maior risco de base da safra, $\mathrm{R} \$ 19,04$.

Patrocínio/MG e Garça/MG apresentaram resultados de base e do risco de base da safra e entressafra, bastante semelhantes, o que vem confirmar uma melhor estrutura da organização, que traz como ponto positivo uma maior estabilidade no processo de comercialização, facilitando as políticas de decisão em relação ao preço da venda do produto. Lavras/MG apresenta uma diferença acentuada entre os resultados de base e do risco de base, o que propicia mais dificuldades para se conseguir a otimização da comercialização do café.

As bases dos meses de vencimento do contrato apresentam valores bastante diferentes em todas as localidades, o que era esperado devido à diferença de qualidade do produto, da distância entre os mercados, ao período de vencimento e à característica intrínseca organização local dos mercados.

O mês de dezembro foi o período que apresentou o maior enfraquecimento de base em todas as localidades devido a um aumento da oferta do produto no mercado físico, pois os cafeicultores têm uma maior necessidade de recursos para pagar o abono salarial e adquirir insumos e também os estoques estão cheios devido à produção passada. A partir da junção desses fatores, cria- se uma pressão para o enfraquecimento da base. 
FONTES, R. E. et al.

TABELA 2 - Base média anual e risco de base anual em R\$/Saca de $60 \mathrm{Kg}$.

\begin{tabular}{|c|c|c|c|c|c|c|c|c|}
\hline \multirow[b]{2}{*}{ Período } & \multicolumn{8}{|c|}{ Localidades } \\
\hline & $\begin{array}{c}\text { Boa } \\
\text { Esperança }\end{array}$ & Caratinga & Lavras & Machado & Patrocínio & Três Pontas & Varginha & Garça \\
\hline \multirow[t]{2}{*}{ Base Média - 94} & ---- & ---- & ---- & $-25,40$ & $-11,91$ & ---- & ---- & $-31,00$ \\
\hline & $(---)$ & $(--)$ & $(---)$ & $(12,67)$ & $(08,15)$ & $(---)$ & $(---)$ & $(14,39)$ \\
\hline \multirow{2}{*}{ Base Média - 95} & ---- & $-09,14$ & $-12,91$ & $-08,51$ & $-09,87$ & ---- & $-14,05$ & $-10,68$ \\
\hline & $(---)$ & $(05,76)$ & $(16,10)$ & $(07,13)$ & $(08,40)$ & $(---)$ & $(14,00)$ & $(04,61)$ \\
\hline \multirow[t]{2}{*}{ Base Média - 96} & $-18,95$ & $-18,24$ & $-09,53$ & $-11,34$ & $-10,17$ & $-21,17$ & $-10,62$ & $-09,53$ \\
\hline & $(00,67)$ & $(08,64)$ & $(07,89)$ & $(07,58)$ & $(08,14)$ & $(00,91)$ & $(13,27)$ & $(09,19)$ \\
\hline \multirow[t]{2}{*}{ Base Média - 97} & $-40,22$ & $-37,87$ & $-49,46$ & $-34,63$ & $-19,91$ & $-28,52$ & $-26,83$ & $-27,04$ \\
\hline & $(25,86)$ & $(30,27)$ & $(00,00)$ & $(11,21)$ & $(09,53)$ & $(05,66)$ & $(12,20)$ & $(09,57)$ \\
\hline \multirow[t]{2}{*}{ Base Média - 98} & $-22,99$ & $-31,31$ & $-34,77$ & $-28,51$ & $-18,06$ & $-25,24$ & $-22,99$ & $-22,39$ \\
\hline & $(13,61)$ & $(17,94)$ & $(20,20)$ & $(07,22)$ & $(09,79)$ & $(08,86)$ & $(16,88)$ & $(09,31)$ \\
\hline \multirow[t]{2}{*}{ Base Média - 99} & $-21,23$ & $-38,40$ & $-32,30$ & $-27,76$ & $-18,53$ & $-27,16$ & $-23,72$ & $-30,23$ \\
\hline & $(14,21)$ & $(14,41)$ & $(18,62)$ & $(15,49)$ & $(10,86)$ & $(13,78)$ & $(26,37)$ & $(16,86)$ \\
\hline \multirow[t]{2}{*}{ Base Média - 00} & $-23,41$ & $-27,77$ & $-20,04$ & $-29,84$ & $-22,39$ & $-30,65$ & $-22,77$ & $-28,72$ \\
\hline & $(07,83)$ & $(10,57)$ & $(07,75)$ & $(06,40)$ & $(09,46)$ & $(07,09)$ & $(13,91)$ & $(12,26)$ \\
\hline \multirow[t]{2}{*}{ Base Média - 01} & $-13,76$ & ---- & $-20,08$ & $-23,91$ & $-09,41$ & ---- & $-06,15$ & $-10,81$ \\
\hline & $(06,93)$ & $(--)$ & $(05,88)$ & $(07,64)$ & $(06,70)$ & $(---)$ & $(09,17)$ & $(05,77)$ \\
\hline
\end{tabular}

FONTE: Dados da pesquisa.

(*) Risco de base

TABELA 3 - Base média por safra e entressafra, base média por mês de vencimento de contrato e risco de base por safra e entressafra em $\mathrm{R} \$ /$ Saca de $60 \mathrm{Kg}$.

\begin{tabular}{|c|c|c|c|c|c|c|c|c|}
\hline \multirow[b]{2}{*}{ Período } & \multicolumn{8}{|c|}{ Localidades } \\
\hline & $\begin{array}{c}\text { Boa } \\
\text { Esperança }\end{array}$ & Caratinga & Lavras & Machado & Patrocínio & Três Pontas & Varginha & Garça \\
\hline Safra & $-21,23$ & $-25,10$ & $-14,70$ & $-22,69$ & $-15,12$ & $-25,95$ & $-17,15$ & $-21,45$ \\
\hline Maio & $-20,32$ & $-29,26$ & $-17,94$ & $-23,96$ & $-13,98$ & $-25,41$ & $-19,07$ & $-18,02$ \\
\hline Julho & $-25,96$ & $-22,99$ & $-13,21$ & $-18,69$ & $-16,18$ & $-26,82$ & $-20,01$ & $-22,74$ \\
\hline Setembro & $-17,65$ & $-22,64$ & $-12,85$ & $-23,28$ & $-15,36$ & $-25,63$ & $-12,04$ & $-23,30$ \\
\hline $\begin{array}{l}\text { Risco de Base } \\
\text { Safra }\end{array}$ & 14,22 & 19,04 & 8,21 & 11,74 & 09,44 & 08,04 & 15,47 & 13,32 \\
\hline Entre Safra & $-28,14$ & $-28,17$ & $-25,91$ & $-26,85$ & $-16,85$ & $-30,41$ & $-22,82$ & $-22,04$ \\
\hline Dezembro & $-29,41$ & $-31,48$ & $-29,57$ & $-31,88$ & $-19,33$ & $-31,64$ & $-30,73$ & $-25,93$ \\
\hline Março & $-26,88$ & $-24,19$ & $-22,87$ & $-22,54$ & $-14,37$ & $-28,87$ & $-16,05$ & $-18,16$ \\
\hline $\begin{array}{l}\text { Risco de Base } \\
\text { Entressafra }\end{array}$ & 20,22 & 14,64 & 19,43 & 13,32 & 11,31 & 10,78 & 17,92 & 14,52 \\
\hline
\end{tabular}

FONTE: Dados da pesquisa.

Ciênc. agrotec., Lavras, v. 29, n. 2, p. 382-389, mar./abr., 2005 


\section{CONCLUSÕES}

A estratégia de utilização do mercado derivativo para comercialização do café mostra-se altamente viável, desde que acompanhado do conhecimento de vários fatores que interferem no mecanismo de comercialização. A utilização dos valores de base local como mais uma ferramenta de auxílio para tomada de decisão na hora da comercialização do café é extremante importante e necessária para que se garanta uma confiabilidade maior na expectativa de preço requerida pelos "hedgers" e, conseqüentemente, traz uma maior procura para a utilização do mercado futuro como alternativa de comercialização, garantindo assim uma maior eficiência e profissionalização no setor comercializador como no setor produtor.

Pelos dados analisados, demonstra-se uma grande variação dos preços físicos e futuros, trazendo uma alta diversidade de valores da base e do risco de base, de forma que cada localidade pesquisada apresenta características próprias, demonstrando a necessidade de se operar em cada mercado físico de forma única.

No geral, o mercado cafeeiro em todas localidades apresenta-se com a base sendo negativa entre o mercado físico da localidade estudada e o mercado futuro da BM\&F.

De um ano para outro, a base média apresenta uma variação de enfraquecimento de base para o fortalecimento de base no ano subseqüente, por causa da característica de bianualidade do cafeeiro, que interfere na oferta do produto e demonstra a necessidade de políticas estratégicas relacionadas ao armazenamento e escoamento do café que permitam uma maior regulação do mercado.

Pelos resultados obtidos, demonstra-se que, de maneira geral, há uma diferença razoável a ser levada em consideração na época de comercialização do café, pois, na safra, o preço do produto é mais estável e a base é mais forte do que na entressafra, que apresenta também um maior risco de base, o que vai ocasionar diferentes estratégias de comercialização.

\section{REFERÊNCIAS BIBLIOGRÁFICAS}

AGUIAR, D. R. D. Mercados futuros como instrumentos de comercialização agrícola no Brasil. In: CONGRESSO BRASILEIRO DE ECONOMIA E SOCIOLOGIA RURAL, 37., 1999, Foz do Iguaçu-PR. Anais... Foz do Iguaçu: [s.n.], 1999. p. 46-57.
ARBEX, M. A.; CARVALHO, V. D. Eficiência do mercado futuro de café brasileiro no período de 1992 a 1998. Revista de Economia e Sociologia Rural, Brasília, v. 37, n. 1, p. 97-113, jan./mar. 1999.

CASTRO JÚNIOR, L. G. de; PERES, F. C.; DIAS, C. T. dos S. Modelo de decisão na maximização de riscos de preço de café. Preços Agrícolas, Piracicaba, v. 11, n. 133, p. 7-16, nov. 1997.

CERTO, S. C.; PETER, J. P. Administração estratégica: planejamento e implantação da estratégia. São Paulo: Makron Books, 1993. 469 p.

FILENI, D. H. O risco de base, a efetividade do heding e um modelo para a estimativa da base: uma contribuição ao agronegócio do café em Minas Gerais. 1999. 137 p. Dissertação (Mestrado em Administração Rural) - Universidade Federal de Lavras, Lavras, 1999.

FONTES, R. E. Estudo econômico da cafeicultura no sul de Minas Gerais. 2001. 94 p. Dissertação (Mestrado em Administração Rural) - Universidade Federal de Lavras, Lavras, 2001.

HULL, J. Introdução aos mercados futuros e de opções. 2. ed. São Paulo: Bolsa de Mercadorias \& Futuros, 1996. $448 \mathrm{p}$.

LEUTHOLD, R. M.; JUNKS, J. C.; CORDIER, J. E. The theory and pratice of futures markets. Massachusetts: Lexington Books, 1989. 410 p.

NUEVO, P. A. S. A cédula do produto rural (CPR) como alternativa para financiamento da produção agropecuária. 1996. 106 f. Dissertação (Mestrado em Economia Agrária) - Escola Superior de Agricultura Luiz de Queiroz, Piracicaba, 1996.

OLIVEIRA, D. P. R. de. Estratégia empresarial. São Paulo: Atlas, 1991. 381 p.

SCHOUCHANA, F. Introdução aos mercados futuros e de opções agropecuários no Brasil. 2. ed. São Paulo: Bolsa de Mercadorias \& Futuros, 2000. 81 p.

TEIXEIRA, M. A. Mercados futuros: fundamentos e características operacionais. São Paulo: Bolsa de Mercadorias \& Futuros, 1992. 53 p. 